\title{
Editorial
}

\section{En tiempos del COVID-19: pandemia e infodemia}

\author{
Alberto A. Marangoni ${ }^{1,2,3}$ \\ 1 Jefe del Servicio de Diagnóstico por Imágenes del Sanatorio Allende, \\ Córdoba, Argentina \\ 2 Universidad Nacional, Córdoba, Argentina \\ ${ }^{3}$ Universidad Católica, Córdoba, Argentina \\ Rev Argent Radiol 2020;84:113-114.
}

En el mes de mayo de 2009, la Organización Mundial de la Salud (OMS) modificó la definición de "pandemia", definiéndola como "la propagación mundial de una nueva enfermedad". Antes se definía como "enfermedad por un agente infeccioso, simultánea en diferentes países, con una mortalidad significativa en relación con la proporción de población infectada" 1 . A su vez, recientemente, la OMS advirtió sobre la "infodemia," un neologismo también conocido como fake news, práctica que consiste en difundir noticias falsas sobre cualquier situación (aplicable hoy a la pandemia) y que tiene como riesgo provocar el pánico en las sociedades.

Debido a la aparición del COVID-19, la infodemia ha invadido el ámbito científico, biológico y médico con una súbita profusión de información acelerada. La mayoría de las veces esta no es corroborada con el rigor científico requerido para una publicación cientifica, sea porque no han cumplido con el ciclo de tiempo para obtener datos sustentables y rigurosamente analizados, sea que no contaron con previa revisión de pares o ambas. Es necesario reconocer que se trata de una situación de emergencia que condujo a una reacción desesperada por transmitir datos que pudieran dar origen a consejos de tratamientos y conductas. Consejos que posibilitaran, a su vez, evitar la catastrófica evolución y el penoso número de seres humanos fallecidos que se fueron sucediendo en los últimos ocho meses, aproximadamente, en todo el mundo.

Esta preocupación quedó manifestada en una nota aclaratoria publicada on-line en Radiology, a cargo del Editorial Board, en la que explican el modo de revisión en 24 horas por parte de los pares revisores, reconociendo las limitaciones temporales relacionadas con este tema. ${ }^{2}$ En concordancia, en Annals of Internal Medicine, publicaron un comentario preciso sobre los riesgos de estas revisiones apresuradas para la publicación de artículos, sin el tiempo deseable para su análisis mesurado. ${ }^{3}$ Esta enorme proliferación de información constituyó un verdadero bombardeo indiscriminado de consejos, de guías de conductas y, en lo que concierne a nuestra especialidad, de interpretación de las imágenes. En efecto, a partir de los hallazgos imagenológicos, se han propuesto rápidamente estadios, relación de extensión de lesiones con la gravedad y el pronóstico de la enfermedad, inteligencia artificial (IA) e, incluso, un intento de creación de RADS. Esto último puede considerarse, sin temor a equivocación, como apresurado y con escaso rigor científico dado que, en condiciones normales, requeriría un mayor tiempo y un análisis más exhaustivo, serio y profundo, antes de ser dados a conocer al mundo científico.

En este contexto, la Sociedad Argentina de Radiología (SAR) y la Federación Argentina de Asociaciones de Radiología, Diagnóstico por Imágenes y Terapia Radiante (FAARDIT) tomaron en conjunto la decisión de crear un Comité SARFAARDIT COVID-19, a cuyo sitio se puede acceder a través de las páginas oficiales de ambas entidades o en forma directa a través del link https://www.sarfaardit-covid19.org/.

La motivación de crear este comité surgió justamente del intento de ordenar y clarificar la información que aparece en la literatura internacional, realizando una especie de filtro previo por parte de un sub-grupo de este comité. Dicho subgrupo se encuentra formado por profesionales con hábito e idoneidad en el análisis de artículos, tratando de entregar a nuestros colegas radiólogos la información más seria y relativamente creíble. La sección "Artículos" posibilita el acceso a dichos trabajos científicos.

Además, también se han constituido otras secciones que permitirán acceder a la consulta con colegas expertos en radiología pulmonar para aquellos radiólogos que necesiten una segunda opinión o compartir algún caso. Esta sección, llamada "Radiología Solidaria", también recopilará los casos comprobados de COVID-19 con radiología y/o tomografía computada (TC). Esto último tendrá por finalidad incluir los datos en una base que permita realizar una casuística propia de pacientes de nuestro país y generar análisis estadísticos a partir de los mismos.

Una sección con el nombre "Webinars" informa sobre las conferencias virtuales que se realizarán con expertos en
Address for correspondence Alberto A. Marangoni, PhD, Jefe del Servicio de Diagnóstico por Imágenes del Sanatorio Allende, Córdoba, Argentina (e-mail: alanmarangoni@gmail. com).
DOI https://doi.org/ 10.1055/s-0040-1714051. ISSN 1852-9992.
Copyright $\odot$ 2020, Sociedad Argentina de Radiología. Publicado por Thieme Revinter Publicações Ltda., Rio de Janeiro, Brazil. Todos los derechos reservados.

\section{License terms}

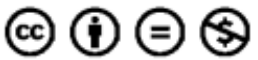


diferentes áreas. En ella, los expertos proveerán su visión y aportes sobre las imágenes, como así también sobre otras disciplinas relacionadas con la problemática general del virus. Estas conferencias están siendo también publicitadas en las redes existentes.

Existe además un "Foro" de discusión y un apartado que propone recomendaciones de cuidado e higiene del personal que actúa en torno a la radiología, la ecografía y la TC, asî como de los equipos que se utilicen para la atención de los pacientes con sospecha o confirmación de COVID-19.

En resumen, los miembros del Comité COVID-19 de ambas sociedades recomiendan el acceso a esta página para tener un contacto firme y directo con las novedades que se vayan sucediendo a través de fuentes óptimas y confiables.

Recientemente, el director general de la OMS, Tedros Adhanom Ghebreyesus, dijo, en una reunión de expertos en política exterior y seguridad en Múnich, que las noticias falsas "se propagan más rápido y más fácilmente que el virus".

Esa es la preocupación y la razón de alerta de las dos instituciones, FAARDITy SAR, que buscan tratar de traer la luz más confiable que ayude a iluminar de buenos resultados a este problema mundial. Un problema lleno de matices y de cambios de paradigmas tan veloces como nunca antes se había experimentado en el campo de la ciencia. Todo es nuevo, todo está por aprenderse y todo puede ser dicho. Pero debemos ser capaces de reconocer la información seria, buena y verdadera, ante tanto caos. Tarea difícil, pero desafío a enfrentar en forma valiente y, sobre todo, honesta.

\section{Bibliografia}

1 Morens DM, Folkers GK, Fauci AS. What is a pandemic? J Infect Dis. 2009;200(07):1018-1021.

2 Moy L, Bluemke D. The Radiology Scientific Expert Panel. Radiology 2020;296(02):E105.

3 Hope MD, Raptis CA, Henry TS. Chest Computed Tomography for Detection of Coronavirus Disease 2019 (COVID-19): Don't Rush the Science. Ann Intern Med 2020;173(02):147-148.

4 La ONU contra la desinformación sobre el COVID-19 y los ataques cibernéticos. https://www.un.org/es/coronavirus/articles/ onu-contra-desinformacion-covid-19-ataques-ciberneticos. Acceso Mayo 13, 2020. 